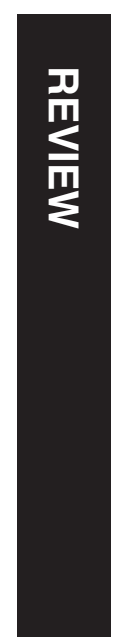

\section{Advances in retinal ganglion cell imaging}

SI Balendra' ${ }^{1}$ EM Normando ${ }^{1,2}$, PA Bloom² and MF Cordeiro ${ }^{1,2}$

progression. Clinically, patients classically experience the progressive loss of their will be bilaterally blind. ${ }^{3}$
${ }^{1}$ Glaucoma and Retinal Neurodegeneration Group, Department of Visual Neuroscience, UCL Institute of Ophthalmology, London, UK

${ }^{2}$ Imperial College Ophthalmology Research Group (ICORG), Western Eye Hospital, Imperial College Healthcare Trust, London, UK

Correspondence: MF Cordeiro, Glaucoma and Retinal

Neurodegeneration Group, Department of Visual

Neuroscience, UCL Institute of Ophthalmology, 11-43 Bath Street, London EC1V 9EL, UK

Tel: +44 (0) 207608 6938;

Fax: +44 (0) 2076086939

E-mail: m.cordeiro@

ucl.ac.uk

Received: 29 June 2015 Accepted: 29 June 2015 Published online: 21 August 2015

\begin{abstract}
Glaucoma is one of the leading causes of blindness worldwide and will affect 79.6 million people worldwide by 2020 . It is caused by the progressive loss of retinal ganglion cells (RGCs), predominantly via apoptosis, within the retinal nerve fibre layer and the corresponding loss of axons of the optic nerve head. One of its most devastating features is its late diagnosis and the resulting irreversible visual loss that is often predictable. Current diagnostic tools require significant RGC or functional visual field loss before the threshold for detection of glaucoma may be reached. To propel the efficacy of therapeutics in glaucoma, an earlier diagnostic tool is required. Recent advances in retinal imaging, including optical coherence tomography, confocal scanning laser ophthalmoscopy, and adaptive optics, have propelled both glaucoma research and clinical diagnostics and therapeutics. However, an ideal imaging technique to diagnose and monitor glaucoma would image RGCs non-invasively with high specificity and sensitivity in vivo. It may confirm the presence of healthy RGCs, such as in transgenic models or retrograde labelling, or detect subtle changes in the number of unhealthy or apoptotic RGCs, such as detection of apoptosing retinal cells (DARC). Although many of these advances have not yet been introduced to the clinical arena, their successes in animal studies are enthralling. This review will illustrate the challenges of imaging RGCs, the main retinal imaging modalities, the in vivo techniques to augment these as specific RGC-imaging tools and their potential for translation to the glaucoma clinic.
\end{abstract}

Eye (2015) 29, 1260-1269; doi:10.1038/eye.2015.154; published online 21 August 2015

\section{Glaucoma, the silent thief}

Glaucoma, commonly termed the 'silent thief of sight', is a leading cause of blindness worldwide. ${ }^{1}$ The disease's asymptomatic nature impedes any forewarning prior to its disabling peripheral visual field, with eventual complete blindness. ${ }^{2}$ It is expected to affect 79.6 million people worldwide by 2020, of which 11.2 million

Glaucoma is a neurodegenerative disorder characterised by the progressive loss of retinal ganglion cells (RGCs). ${ }^{4,5}$ Increased RGC apoptosis and axonal loss within the inner retina is the earliest form of cell death in glaucoma, and it directly correlates with clinical severity of the disease. ${ }^{3}$ Although apoptosis is a key component of homoeostasis in normal development and aging, its dysregulation is implicated in a vast range of leading ophthalmic and systemic disorders, including age-related macular degeneration, retinitis pigmentosa, cancer, neurodegeneration, and automimmune diseases. ${ }^{6-8}$ As apoptosis has such a major role in glaucoma, its early identification in vivo would be a key goal for biomedical research that will certainly enhance clinical diagnostics and could be an end point for novel neuroprotective strategies. Part of the diagnostic challenge, however, includes the lack of knowledge about the precise pathophysiology that leads to RGC apoptosis in glaucoma.

Elevated intraocular pressure is directly related to disease progression and is the most important and only modifiable risk factor for glaucoma. ${ }^{9}$ However, glaucoma progression can still occur in patients with drug-controlled intraocular pressure and in patients with normotensive glaucoma. Therefore, intraocular pressure is an inadequate measurement tool to diagnose or monitor its progression. Current instrumental diagnostic methods are divided into structural and functional types, which are based on the measurement of the retinal nerve fibre layer (RNFL) and neuro-retinal rim thickness, and visual field loss respectively, to approximate RGC loss and the extent of the disease. However, these methods have low sensitivity, requiring significant RGC loss (25-40\%) before showing evidence of disease. ${ }^{10,11}$ It is estimated that in the developed world only 
one-half of people affected by glaucoma are aware of their condition and that there is a 10-year delay between initial onset and diagnosis of glaucoma. ${ }^{12}$ By this time, irreversible blindness can occur. There remains a clear and unmet need to establish an earlier diagnostic tool.

The eye is an ideal organ for non-invasive imaging. The ocular physics and transparency facilitate the eye to be the 'window to the central nervous system',13 in which only minor manipulations are required for improved light transmission and optical quality, such as pupil dilation and corneal hydration. This advantage can be exploited to establish retinal imaging tools that will provide an insight into the health and functionality of not just the retinal neurons, but also the entire central nervous system. The ideal retinal imaging technique should be noninvasive, consistent, sensitive, cell-specific, confer high-resolution, and have the capacity for longitudinal in vivo monitoring. ${ }^{14}$ Recent advances are likely to provide novel earlier diagnostic biomarkers for glaucoma and therefore earlier disease intervention. Retinal imaging in vision research has evolved substantially over the last few decades from a macroscopic to microscopic single-cell imaging level. This review will provide an overview of RGC-imaging techniques and recent advances and describe the challenges and promises of translating these from the laboratory bench to the patient bedside.

\section{Retinal ganglion cells}

The human retina contains $\sim 1.5$ million RGCs, which are not confined to 1 of the 10 distinct retinal layers. ${ }^{15}$ Several experimental studies have indicated that RGC apoptosis occurs in the ganglion cell layer in glaucoma. ${ }^{4,5,16}$ RGCs are transparent and do not have any particular discriminating optical property. Indeed, the low contrast of the inner retinal layers renders traditional imaging methods, such as fundus photography, confocal scanning laser ophthalmoscopy (cSLO) or laser polarimetry, inadequate to visualise them. This has led to the need to establish specific RGC markers to accurately visualise, diagnose and monitor RGC apoptosis in glaucoma. As detailed in Table 1, recent advances, however, have enabled us to visualise photoreceptors (direct visualisation with adaptive optics-cSLO) or fluorescently labelled RGCs (transgenic models, exogenous markers). ${ }^{10,17-19}$

The ability to monitor RGC health accurately longitudinally in vivo confers numerous benefits. First, our understanding of the natural history of glaucoma would be enhanced, perhaps highlighting spatial patterns of retinal cell death over days, weeks, and years. Second, this could also be used as a tool to reliably measure the neuroprotective efficacy of therapeutic agents. ${ }^{10,18,20,21}$ In current clinical practice or in animal models of glaucoma, the tools available for quantification of the degree of neuroprotection are inadequate. For example, in the large-scale Low-pressure Glaucoma Treatment Study, the primary end point was progression of visual field loss. ${ }^{22}$ This required a 4 -year follow-up, in which visual field loss was used as a surrogate for end-stage disease. This was echoed in the recent large-scale clinical trial UKGTS, in which a 2-year follow-up was required to assess the efficacy of latanoprost compared with placebo. ${ }^{23}$ Although the observation period was shorter than prior studies, it remains an unsuitably prolonged time frame to identify any therapeutic effect. Third, instead of a single snapshot, long-term measurement of RGC status would provide a more accurate interpretation of retinal health or disease status. There is a large variation in density of RGCs and normal pattern of age-dependent RGC loss among individuals. ${ }^{24}$ Therefore, monitoring deviation of RGC loss from an individually established baseline is the most appropriate measure. ${ }^{25-27}$ Finally, there are pathogenic similarities between glaucoma and other neurodegenerative diseases, such as Alzheimer's disease; therefore this method could be translated to other conditions to advance our understanding of specific patterns of cell loss and therapeutic efficacies. There is hope that with the use of a tool to accurately measure RGC health in glaucoma patients, monitoring of disease progression and screening of individuals at high-risk of disease can be accurately performed.

\section{Retinal imaging modalities}

\section{Optical coherence tomography}

Optical coherence tomography (OCT) constitutes several different image modalities and broadly falls into two main categories: time- and spectral-domain, each of which refers to the relevant detection of the OCT signal. This image modality was developed over 20 years ago and has been increasingly used for RNFL analysis in glaucoma. ${ }^{28}$

The principle of OCT is that it generates cross-sectional two-dimensional images from the optical backscattering of light and echo time delay, capturing images with very high axial resolution of $1-15 \mu \mathrm{m} \cdot{ }^{29,30}$ It provides a rapid, reproducible, inexpensive, and non-invasive retinal imaging tool. It is based on low-coherence interferometry, in which light is split from one beam into two different paths, and then recombined, creating interference patterns. Two-dimensional images may be formed with ultrasound-like A scans, or otherwise a three-dimensional image may be formed with sufficient B scans. However, the weakly backscattering nature and low-contrast edges of cells prevent the direct visualisation of individual RGCs. In spite of this, spectral-domain OCT has been 
Table 1 Summary of the main retinal imaging modalities and in vivo RGC labelling tools

\begin{tabular}{|c|c|c|c|c|c|}
\hline $\begin{array}{l}\text { Retinal Imaging/ } \\
\text { RGC labelling type }\end{array}$ & Summary & Resolution & Advantages & Disadvantages & $\begin{array}{l}\text { First study } \\
\text { of retinal } \\
\text { use }\end{array}$ \\
\hline OCT & $\begin{array}{l}\text { Non-invasive cross-sectional } \\
\text { measurements of biological } \\
\text { structures by assessing } \\
\text { optical reflectance with } \\
\text { low-coherence inter- } \\
\text { ferometry. Can be combined } \\
\text { with recent advances: } \\
\text { angiography OCT, Doppler } \\
\text { OCT, polarisation-sensitive } \\
\text { OCT, Fourier domain, } \\
\text { swept-source, long- } \\
\text { wavelength, eye tracking, } \\
\text { image registration. }\end{array}$ & $\begin{array}{l}\text { High axial resolution } \\
\text { of } 1-15 \mu \mathrm{m}\end{array}$ & $\begin{array}{l}\text { Rapid, consistent, cheap, } \\
\text { non-invasive }\end{array}$ & $\begin{array}{l}\text { Poor lateral resolution; } \\
\text { cannot visualise RGCs }\end{array}$ & $1991^{28}$ \\
\hline cSLO & $\begin{array}{l}\text { Most commonly used retinal } \\
\text { imaging technique involving } \\
\text { retinal scanning with a } \\
\text { narrow laser beam and } \\
\text { capturing the light through a } \\
\text { small aperture, which } \\
\text { reduces scattered light from } \\
\text { outside focal plane. Can be } \\
\text { combined with endogenous } \\
\text { or exogenous specific cell } \\
\text { markers. }\end{array}$ & High lateral resolution & $\begin{array}{l}\text { Very high resolution, sharp } \\
\text { high-contrast images, non- } \\
\text { invasive, patient comfort } \\
\text { from less-bright light, 3D, } \\
\text { and video-imaging } \\
\text { capacity }\end{array}$ & $\begin{array}{l}\text { Poor axial resolution; cannot } \\
\text { visualise RGCs }\end{array}$ & $1980^{38}$ \\
\hline Adaptive optics & $\begin{array}{l}\text { Corrects optical aberrations } \\
\text { when combined with OCT } \\
\text { or cSLO combined with } \\
\text { deformable mirrors and } \\
\text { wavefront analysis. }\end{array}$ & $\begin{array}{l}\text { Lateral resolution of } \\
<1 \mu \mathrm{m}\end{array}$ & $\begin{array}{l}\text { Improved penetration and } \\
\text { resolution; can visualise } \\
\text { cone photoreceptors; } \\
\text { smaller speckle, increased } \\
\text { sensitivity to weak } \\
\text { reflections }\end{array}$ & $\begin{array}{l}\text { Costly, requires technical } \\
\text { expertise, difficult image } \\
\text { acquisition in patients with } \\
\text { ocular opacities such as } \\
\text { dense cataracts or with } \\
\text { unstable fixation }\end{array}$ & $1990 s^{48}$ \\
\hline Retrograde labels & $\begin{array}{l}\text { Injection of lipophilic dyes } \\
\text { within visual pathway, } \\
\text { which track along RGC axon } \\
\text { to cell body in retina. }\end{array}$ & $\begin{array}{l}\text { Labels individual } \\
\text { RGCs }\end{array}$ & $\begin{array}{l}\text { High sensitivity of RGC } \\
\text { labelling }\end{array}$ & $\begin{array}{l}\text { Invasive; harmful; non- } \\
\text { specific to RGC; for animal } \\
\text { models only }\end{array}$ & $1997^{64}$ \\
\hline $\begin{array}{l}\text { Transgenic } \\
\text { models }\end{array}$ & $\begin{array}{l}\text { Promote expression of } \\
\text { RGC-specific markers, for } \\
\text { example, Brn3b, Thy1, ckit. }\end{array}$ & $\begin{array}{l}\text { Single-cell } \\
\text { fluorescence resolution }\end{array}$ & $\begin{array}{l}\text { High sensitivity of RGC } \\
\text { labelling; non-invasive }\end{array}$ & $\begin{array}{l}\text { For animal models only; } \\
\text { non-specific to RGCs; } \\
\text { transient }\end{array}$ & $2008^{42}$ \\
\hline Electroporation & $\begin{array}{l}\text { Voltage application across } \\
\text { membranes allowing } \\
\text { transfection of contrast } \\
\text { agents or vectors into cells. }\end{array}$ & $\begin{array}{l}\text { Potential to achieve } \\
\text { individual cell } \\
\text { resolution }\end{array}$ & $\begin{array}{l}\text { Rapid, cheap, high } \\
\text { transfection rates }\end{array}$ & $\begin{array}{l}\text { Non-specific to RGCs; } \\
\text { potentially harmful; for } \\
\text { animal models only }\end{array}$ & $2002^{74}$ \\
\hline $\begin{array}{l}\text { Intravitreal } \\
\text { neuronal marker }\end{array}$ & $\begin{array}{l}\text { Intravitreally injected } \\
\text { marker, CTB, tags retinal } \\
\text { cells when combined with } \\
\text { cSLO. }\end{array}$ & Labels individual cells & $\begin{array}{l}\text { Single-cell fluorescence } \\
\text { resolution }\end{array}$ & $\begin{array}{l}\text { Invasive; non-specific to } \\
\text { RGCs }\end{array}$ & $2015^{84}$ \\
\hline DARC & $\begin{array}{l}\text { Intravenous administration } \\
\text { of fluroescently tagged } \\
\text { annexin-V labels apoptotic } \\
\text { RGCs, with subsequent } \\
\text { identification with cSLO. } \\
\text { In Phase } 1 \text { Clinical Trials }\end{array}$ & $\begin{array}{l}\text { Labels individual } \\
\text { apoptosing RGCs }\end{array}$ & $\begin{array}{l}\text { Non-invasive, quantifiable, } \\
\text { single-cell fluorescence } \\
\text { resolution }\end{array}$ & $\begin{array}{l}\text { Normal healthy range of } \\
\text { apoptotic cells needs to be } \\
\text { established }\end{array}$ & $2004^{10}$ \\
\hline CapQ & $\begin{array}{l}\text { Cell penetrating, caspase- } \\
\text { activated apoptotic probe to } \\
\text { label apoptotic cells when } \\
\text { combined with cSLO }\end{array}$ & $\begin{array}{l}\text { Labels individual } \\
\text { apoptosing RGCs }\end{array}$ & $\begin{array}{l}\text { Single-cell fluorescence } \\
\text { resolution }\end{array}$ & Probe toxicity & $2005^{97}$ \\
\hline
\end{tabular}

Abbreviations: cSLO, confocal scanning laser ophthalmoscopy; CTB, cholera toxin subunit B; DARC, detection of apoptosing retinal cells; OCT, optical coherence tomography; RGC, retinal ganglion cell; Thy1, THYmocyte differentiation antigen 1. 
valuable in providing high-resolution and reproducible images to monitor RNFL thickness longitudinally in experimental and clinical glaucoma. ${ }^{31-34}$ Furthermore, notable technological advances, including eye tracking and image registration for precise follow-up imaging, have increased resolution and reduced noise and motion artefact. Strides have been taken to add vascular flow to images with the introduction and development of Doppler OCT. ${ }^{35}$ Polarisation-sensitive OCT is also of major interest, as ocular structures alter the polarisation state of the light and thereby add a tissue-specific contrast to the images, which could enable densities of RGC axons to be measured. ${ }^{36}$ Long-wavelength OCT also appears to be beneficial, by reducing scattering and allowing deeper tissue penetration. ${ }^{37}$ Swept-source OCT is one the latest milestones in OCT technology. Tunable long-wavelength is used to further increase resolution. The scan speed is twice that of spectral-domain OCT, allowing improved resolution and better tissue penetration.

\section{Confocal scanning laser ophthalmoscopy}

Confocal scanning laser ophthalmoscopy (cSLO) is the most extensively used retinal imaging technique. Despite being established in $1980,{ }^{38}$ cSLO's adaptability has qualified its survival within the rapidly evolving field. Its departure from traditional ophthalmoscopy and fundus photography and its resulting high-resolution images enable it to detect subtle retinal changes, firmly positioning itself as a key diagnostic tool in glaucoma. ${ }^{39}$ cSLO's underlying methodology is based on the confocal microscopy technique. The light source is a point source laser and its beam is scanned onto the retina. The pinhole is in front of the photodetector and allows the detection of the light coming from a specific depth.

Although retinal imaging methods such as ophthalmoscopy involve a much larger illumination area compared with the observation area, this technique is inverted. The illumination of the retina with a moving narrow beam of light and its subsequent detection follow the same path, thereby eliminating scattered light and ensuring light from the focal plane only is detected. This achieves high lateral resolution compared with conventional fundus photography, enabling the production of topographic images. ${ }^{40}$ However, axial resolution of conventional cSLO is poor. cSLO is a commonly used tool to measure the optic nerve head and RFNL thickness, by creating three-dimensional topographies. ${ }^{41}$

cSLO is well suited to enhancement with fluorescent markers. Several research groups have used this combination to detect apoptotic RGCs in vivo using endogenous or exogenous labels and to longitudinally monitor rodent RGCs in vivo. ${ }^{10,20,21,42-45}$ It is a popular tool in clinical practice, owing to its versatility to be used with a number of types of laser wavelengths and filters. Limitations of its usage only include pupil diameter and ocular opacities. As discussed below, the future of cSLO, however, lies in adaptive optics (AO), in the ability to alter the scanning amplitude speed and modify the pinhole size. $^{46}$

\section{Adaptive optics}

Many advances in both cameras and optics have been achieved over the past few decades to attain the current standards of imaging techniques. AO is one such advance that has improved both OCT and SLO. ${ }^{47}$ Its origin lies in astronomy, in which it was developed to reduce the speckle from light in the atmosphere when viewing objects in space via telescopes. It was later introduced into the ophthalmological arena in the mid-1990s to reduce optical aberrations by using active optical components. Since then, it has enhanced all types of retinal imaging modalities, including the subtypes of OCT.

$\mathrm{AO}$ involves the detection of intrinsic optical aberrations by analysing the light wavefront coming from the eye and its correction using electro-actuated deformable mirrors, most commonly in a ShackHartmann configuration. ${ }^{48}$ Its optimal usage is when the patient's pupil is $>6 \mathrm{~mm}$, so as to minimise diffractive error. AO confers three main technical advantages:

(1) improved lateral and axial resolution of retinal images,

(2) smaller speckle, and (3) enhanced sensitivity to weak reflections. In combination with cSLO and OCT, it can improve the resolution of fine detail in vivo. ${ }^{47}$ For example, AO-OCT has a lateral resolution up to five times compared with standard OCT systems. Unprecedented resolution of $2-3 \mu \mathrm{m}$ may be achieved, allowing direct visualisation of individual cells without the need for an exogenous label. When used with OCT, resolution can be improved, such that individual nerve fibre bundles are observed in humans in vivo. ${ }^{49,50}$ When combined with cSLO, fluorescently labelled rodent capillaries, and dendrites of microglial cells can be visualised in vivo at high resolution. ${ }^{51}$ Furthermore, cone photoreceptor cells have been directly observed using AO-SLO via their intrinsic reflectance properties. ${ }^{52}$ Its application in monkeys and humans has allowed us to better characterise the photoreceptor mosaic spacing in the macula region. 47,52

$\mathrm{AO}$ has great potential to enhance imaging in glaucoma. It may be used to analyse the RNFL, providing improved penetration and resolution, leading to better definition of subtle changes. In a recent clinical study of glaucoma patients, it was demonstrated that AO-SLO revealed pathological details that were unable to be differentiated by OCT. ${ }^{53}$ The improved penetration and 
resolution allow greater definition of subtle retinal changes. There has been substantial research by several groups to construct three-dimensional microscopic structures, which would permit improved detection and monitoring of damage to the nerve fibres. ${ }^{54}$

Since its initial use within vision research, $\mathrm{AO}$ has taken great strides in development and accomplishments, such that its imminent ophthalmic commercialisation is palpable. It is evident that the future of cSLO lies in AO, although a lot of research is going into small aperture fast scanning cSLO. ${ }^{46}$ Fluorescent markers may have a role in the future to improve this technique further.

\section{RGC in vivo labelling}

As mentioned above, imaging RGCs remains a challenge due to their inherent transparent nature. Specific RGC labelling techniques can be combined with the retinal imaging modalities described above to enhance information gained. For example, in general medical and surgical specialties, contrast agents are widely used to enrich structural and functional information gleaned from positron emission tomography, computed tomography and magnetic resonance imaging. Comparatively, within clinical ophthalmology, fluorescein, and indocyanine green angiography remain the only investigations in which such dyes are utilised. The incorporation of contrast agents to label-specific cell types via a systemic or intraocular route has the potential to add a new dimension to retinal and RGC imaging and aid diagnosis, detection, and accurate monitoring of disease progression. Such in vivo labelling may be suitable for specifically identifying healthy or unhealthy cells, each of which will be discussed in turn here. Experimental techniques of healthy cell labelling in vivo include transgenic models, retrograde labels, and electroporation. Imaging of specifically unhealthy cells in vivo may be performed with fluorescent labels, including CapQ and Annexin-A5. Annexin-V is currently in DARC Phase I clinical trials.

These techniques constitute valuable mechanisms to study longitudinal pathological mechanisms of glaucoma and other forms of neurological and retinal degeneration. However, although their usage so far has currently been limited to experimental animal models mainly for studying cellular projections and apoptosis, the results have been exciting.

\section{Imaging healthy cells}

An in vivo ocular biomarker for imaging healthy RGCs would prove optimal for monitoring RGC health in live animals or patients.
Retrograde tracers Retrograde labelling involves the direct application of lipophilic neuronal dyes to the visual pathway and is a well-established tool in histological and animal studies for quantification of RGCs and estimation of their density. Its limitation is that it cannot be translated to use in humans, but it has broadened our knowledge in vision research.

Different types of dyes have been used, particularly those that are fluorescent, which are actively transported within cells, ${ }^{55}$ such as Carbocyanine dyes, including DiAsp (4-[4-didecylaminos- tyryl]- $N$-methyl-pyridinium iodide), DiI (1,1'-dioctade- cyl-3,3,3',3'-tetramethylindocarbocyanine perchlorate), $\mathrm{DiO}\left(3,3^{\prime}\right.$ -

dioctadecyloxacarbocyanine perchlorate) and Fluorogold. They are incorporated into the cell membrane and subsequently actively transported within cells through the axons as the lipids are recycled. ${ }^{56}$ Hydrophilic dyes, such as rhodamine dextran, have also been used in primate retina to visualise RGCs. ${ }^{57}$

Previously, most retrograde labels were used ex vivo; however, increasingly more studies have been successfully using this method in vivo. ${ }^{18,44,58}$ Their commonest method of application involves injection high up in the visual pathway, where they then travel up the length of the RGC axon to reach the cell body within the retina. ${ }^{56,59-61}$ This mode of application is commonly used to study experimental glaucoma. ${ }^{18,44,58,62}$ In a chronic ocular hypertensive model of neurodegeneration, RGCs were fluorescently labelled by directly injecting DiI into the rat superior colliculi. ${ }^{63}$ cSLO was used to analyse the retinas at intervals over 8 weeks from induction of elevated intraocular pressure, after which time there was significant RGC loss. Other studies have demonstrated successful application to the superior colliculi, $44,64,65$ lateral geniculate nucleus, ${ }^{18}$ or the optic nerve. ${ }^{55}$

In some cases, retrograde labelling has been considered suboptimal, owing to incomplete RGC dye uptake. This is frequently due to the difficulty in labelling multiple central RGC targets. However, in recent studies, labelling of rodent RGCs with these methods have been shown to be highly effective, with 100 and $96 \%$ of RGC labelling estimated following direct injection into transected optic nerve stump and superior colliculus application, respectively. ${ }^{66,67}$ Despite RGCs being highly sensitive to labelling, cell specificity appears to suffer. After RGC death, phagocytic cells, including microglia and macrophages, migrate to the area and ingest the fluorescent dendrites, leading to false positives. ${ }^{68,69}$ This challenges the accuracy of longitudinal in vivo monitoring alongside the hazardous surgical application methods of retrograde labelling, which limit its translation to the clinical arena. However, the knowledge gathered from experimental work is beneficial. 
Transgenic models Transgenic models have been widely used across many scientific research fields to control the expression of specific genes. Under the control of specific RNA promoters, the expression of fluorescent proteins, such as green fluorescent protein, can act as a cell-specific marker for RGCs, which is invaluable for glaucoma diagnostic research. Commonly used RGC-specific markers include THYmocyte differentiation antigen 1 (Thy1), ckit, and Brn3b in rodents. ${ }^{18,19,70}$

Several transgenic mouse models, generated using the Thy1 promoter to drive fluorescent probe expression, have led to high levels of RGC labelling. Transgenic mice expressing cyan fluorescent protein driven by Thy1 promoter were imaged with cSLO to contrast-enhance RGCs and differentially label different neuronal subtypes. ${ }^{17}$ This permits investigation into whether specific subtypes of RGCs are more susceptible to disease. Cyan fluorescent protein expression in rodent RGCs achieved high sensitivities, with $\sim 90 \%$ of cells labelled. However, similar to retrograde labelling, there was reduced specificity, with displaced amacrine cells and microglia being among the non-RGC cells also labelled, the latter being due to phagocytosis of the apoptotic labelled neurons. ${ }^{69}$

Leung et al. ${ }^{71}$ showed in their recent study of transgenic Thy1-yellow fluorescent protein mice that when combined with cSLO, this proved to be a robust way of monitoring RGC survival and morphology. cSLO- and spectral domain OCT-imaged fluorophore-expressing transgenic mice is also used to longitudinally measure density and RNFL thickness following optic nerve injury. ${ }^{31,72,73}$ This method of cell-specific contrast enhancement is advantageous as it permits non-invasive and longitudinal monitoring. However, in some studies transgenic labelling has been transient, and not lasted for long enough for adequate longitudinal observations.

Evidently, transgenic models cannot be applied to humans due to it being unacceptable to modify human genes for the purposes of cell labelling. However, results of these studies provide valuable transferrable information for understanding glaucoma and developing new imaging modalities.

Electroporation Electroporation is an inexpensive and highly repeatable technique under well-controlled conditions, in which a voltage is applied across a membrane, leading to the transfection of ectopic genes or contrast agents into cells in vivo. In the eye, contrast agents can be delivered rapidly with high efficacy and good safety profile. ${ }^{74-77}$ It can achieve $90 \%$ transfection rates and rapid expression in cultured photoreceptor cells. ${ }^{75}$ In vivo rodent studies have shown $41.5 \%$ transfection of RGCs in the area affected by electroporation was achieved. ${ }^{74}$ Contrast agents may be administered via subretinal or intravitreal injection, depending on location of the target retinal cells. ${ }^{78}$ A disadvantage with this method is that it can potentially be a harmful technique. RGCs are post-mitotic cells and are therefore unable to proliferate if damaged. Unlike other larger body tissues, such as muscle or liver, electrical pulses of $50-100 \mathrm{mV}$ can result in an inflammatory response of the eyeball, therefore much smaller pulses of $\sim 12 \mathrm{mV}$ would be optimal. ${ }^{74}$ Another disadvantage is its lack of specificity to a particular cell type, such as RGCs. ${ }^{79}$ Similarly to the labelling techniques described above, electroporation is also only limited to animal studies, in which it is a useful method of studying retinal cells including RGCs.

Intravitreal RGC markers Several endogenous genetic and protein RGC-specific markers have been established, most notably the RGC nuclear marker brain-specific homeobox/POU domain protein 3A (Brn3a) ${ }^{80}$ and $\gamma$-synuclein. ${ }^{81}$ Currently, they are extensively used for immunohistochemistry ex vivo in post-mortem human and rodent retinas and in the future may be useful as promoters to target the expression of fluorescent markers to label normal RGCs. ${ }^{82}$ Antibodies to RNAbinding protein with multiple splicing have also been used to robustly identify RGCs ex vivo in rodent retinas. ${ }^{83}$

A recent study demonstrated that healthy RGCs in wild-type mice were efficiently labelled in vivo with noninvasive imaging, following intravitreal injection of a neuronal marker CTB. ${ }^{84}$ Cholera toxin subunit B was conjugated to a fluorescent tag and used to label RGCs specifically. It is non-toxic to cells and has been previously administered to patients safely. ${ }^{85,86}$ Over half of labelled cells were RGCs, as confirmed by comparison with immunohistochemistry staining RNA-binding protein with multiple splicing. Although it was found that this labelling is not specific to RGCs, as it also labelled amacrine cells, it promises to be an efficient and consistent potential technique for in vivo non-invasive healthy RGC imaging.

\section{Imaging unhealthy cells}

Although the imaging of healthy RGCs can approximate general retinal health, the imaging of specifically unhealthy RGCs would be more sensitive of detecting subtle defects and early disease.

Ocular biomarkers of glaucoma Biomarkers are endogenous anatomic, physiological, biochemical indicators that are associated with specific disease states. ${ }^{14,87}$ They provide an objective measurement, via laboratory assays or imaging techniques, to detect disease early and monitor therapeutic efficacy. The optimal 
biomarker is specific, sensitive, and reproducible, as well as inexpensive and non-invasive. A biomarker for glaucoma should indicate the rate of RGC loss and the number of remaining or apoptotic RGCs with high sensitivity.

Fluorescent markers Recently, there have been significant advances in fluorescent technology to identify single RGCs undergoing apoptosis. These will prove invaluable in experimental models as well as in a clinical environment.

The recent development of DARC could potentially have a significant impact on the clinical diagnostics of patients with glaucoma and other neurodegenerative diseases. ${ }^{10}$ DARC is a novel non-invasive real-time imaging technique to measure RGC apoptosis in vivo. It has the potential to identify disease in its early stages end could eventually lead to the establishment of novel therapeutic strategies to alter its course of irreversible blindness. DARC is currently in Phase I clinical trials (NCT02394613). ${ }^{43}$

DARC involves the intravenous injection of fluorescently labelled annexin-5, which binds to apoptosing cell plasma membranes, followed by retinal examination by cSLO. Each resulting fluorescent spot on the retinal image attained represents a bound annexin- 5 and therefore a single-apoptotic RGC. These fluorescent spots are then counted, providing a quantitative measure of RGC disease. Annexin-5 is an endogenous extracellular calcium-dependent membrane-binding protein that can bind negatively charged phosphatidyserine with high affinity. ${ }^{88}$ During early apoptosis, phosphatidyserine translocates from the inner to the outer plasma membrane, where it is exposed to the extracellular domain. This is one of the initial steps of the apoptotic cascade, and a much earlier marker than lateapoptosis markers such as DNA fragmentation detected by terminal deoxynucleotidyl transferase dUTP nick end labelling. ${ }^{89}$ Annexin-5's intravenous administration has been used in large-scale clinical trials, which have indicated its ability to cross the blood-brain barrier and its tolerability and safety. ${ }^{90}$ The intravenous route of administration is also widely accepted within ophthalmology, such as for fluroscein and indocyanine green angiography. ${ }^{91}$

In a number of experimental studies, DARC has been demonstrated to be a valuable end point in the investigation of neuroprotective therapeutic agents in glaucoma models and in the relationship between Alzheimer's disease and glaucoma. ${ }^{10,13,20,21,45,63,92,93}$ However, the proportion of apoptosing cells in healthy compared with glaucomatous eyes is yet to be fully investigated, therefore, large-scale clinical trials will be needed to assess longitudinal DARC measurements and its capability of differentiating between pathological glaucomatous RGC apoptosis and age-dependent RGC decay. If it also then correlates with patterns of RGC axonal loss, it may be determined to be a reliable early marker of disease and thus its robustness to assess neuroprotective agents would be widely used. ${ }^{94}$

CapQ technology CapQ, a cell-penetrating, caspaseactivated apoptotic probe, is another technique to label apoptotic cells. ${ }^{95}$ This technology consists of a cellpenetrating peptide, conjugated to an effector caspase recognition sequence that is flanked by a flurophorequencher pair. It is activated by effector caspases in apoptotic cells, and cSLO can be used to detect its fluorescence. After intravitreal injection of TcapQ488, a novel probe redesigned for current imaging techniques, single-cell apoptosing RGCs were successfully detected in vivo using cSLO in mouse models of retinal degeneration. ${ }^{96}$ This was found to be associated with minimal toxicity. However, probe-activation also occurred in wild-type rodent eyes, which may be caused by probe-related toxicity, leading to apoptosis. This novel technique has the potential to report RGC apoptosis in vivo and therefore aid glaucoma diagnostics. However, its intracellular and cellular penetrating abilities reduce its likelihood of usage in humans.

\section{Conclusion}

Glaucoma is a disease that places a great burden on healthcare resources worldwide, which is exacerbated by delays in diagnosis. In this review we have summarised key developments in retinal imaging modalities and RGC endogenous and exogenous labelling. Although many of these have only been observed experimentally in animals so far, imaging RGCs in vivo is a fast evolving field of ophthalmological research and holds high clinical translational potential. Not only can recent advances provide great hope for clinical diagnostics, screening, and monitoring in glaucoma, but also in other neurodegenerative diseases, which may affect retinal health. Early diagnosis and detection of subtle retinal defects could signal disease onset at a pre-clinical stage, prior to the development of irreversible destructive damage. This could alert clinicians to begin earlier therapeutic interventions, reducing the severity of the inevitable development of visual loss or blindness in glaucoma and the financial burden of the disease while significantly improving patients' quality of life. For ophthalmological research scientists, clinicians, and patients, the next decade will prove to be exciting. 


\section{Conflict of interest}

The authors declare no conflict of interest.

\section{References}

1 Pascolini D, Mariotti SP. Global estimates of visual impairment: 2010. Br J Ophthalmol 2011; 96(5): 614-618.

2 Foster PJ, Buhrmann R, Quigley HA, Johnson GJ. The definition and classification of glaucoma in prevalence surveys. Br J Ophthalmol 2002; 86(2): 238-242.

3 Quigley HA, Broman AT. The number of people with glaucoma worldwide in 2010 and 2020. Br J Ophthalmol 2006; 90(3): 262-267.

4 Garcia-Valenzuela E, Shareef S, Walsh J, Sharma SC. Programmed cell death of retinal ganglion cells during experimental glaucoma. Exp Eye Res 1995; 61(1): 33-44.

5 Quigley HA, Nickells RW, Kerrigan LA, Pease ME, Thibault DJ, Zack DJ. Retinal ganglion cell death in experimental glaucoma and after axotomy occurs by apoptosis. Invest Ophthalmol Vis Sci 1995; 36(5): 774-786.

6 Humayun MS, Prince M, De Juan Jr E, Barron Y, Moskowitz M, Klock IB et al. Morphometric analysis of the extramacular retina from postmortem eyes with retinitis pigmentosa. Invest Ophthalmol Vis Sci 1999; 40(1): 143-148.

7 Medeiros NE, Curcio CA. Preservation of ganglion cell layer neurons in age-related macular degeneration. Invest Ophthalmol Vis Sci 2001; 42(3): 795-803.

8 Fischer U, Schulze-Osthoff K. New approaches and therapeutics targeting apoptosis in disease. Pharmacol Rev 2005; $57(2):$ 187-215.

9 Quigley HA. Glaucoma. Lancet 2011; 377(9774): 1367-1377.

10 Cordeiro MF, Guo L, Luong V, Harding G, Wang W, Jones HE et al. Real-time imaging of single nerve cell apoptosis in retinal neurodegeneration. Proc Natl Acad Sci USA 2004; 101(36): 13352-13356.

11 Harwerth RS, Carter-Dawson L, Shen F, Smith EL 3rd, Crawford ML. Ganglion cell losses underlying visual field defects from experimental glaucoma. Invest Ophthalmol Vis Sci 1999; 40(10): 2242-2250.

12 Kerrigan-Baumrind LA, Quigley HA, Pease ME, Kerrigan DF, Mitchell RS. Number of ganglion cells in glaucoma eyes compared with threshold visual field tests in the same persons. Invest Ophthalmol Vis Sci 2000; 41(3): 741-748.

13 Guo L, Duggan J, Cordeiro MF. Alzheimer's disease and retinal neurodegeneration. Curr Alzheimer Res 2010; 7(1): 3-14.

14 Heaton GR, Davis BM, Turner LA, Cordeiro MF. Ocular biomarkers of Alzheimer's disease. Cent Nerv Syst Agents Med Chem 2015; 15(2): 117-125.

15 Massey SC. Functional Anatomy of the Mammalian Retina In: Sjrrhpsp Wilkinson (ed). Retina 4th edn, Chapter 4. Mosby: Edinburgh, Scotland, 2006, pp. 43-82. Available from: http:/ / www.sciencedirect.com/science/article/pii/ B9780323025980500100.

16 Jakobs TC, Libby RT, Ben Y, John SWM, Masland RH. Retinal ganglion cell degeneration is topological but not cell type specific in DBA/2J mice. J Cell Biol 2005; 171(2): 313-325.

17 Feng G, Mellor RH, Bernstein M, Keller-Peck C, Nguyen QT, Wallace $\mathrm{M}$ et al. Imaging neuronal subsets in transgenic mice expressing multiple spectral variants of GFP. Neuron 2000; 28 (1): 41-51.
18 Gray DC, Merigan W, Wolfing JI, Gee BP, Porter J, Dubra A et al. In vivo fluorescence imaging of primate retinal ganglion cells and retinal pigment epithelial cells. Opt Express 2006; 14 (16): 7144-7158.

19 Kerrison JB, Duh EJ, Yu Y, Otteson DC, Zack DJ. A system for inducible gene expression in retinal ganglion cells. Invest Ophthalmol Vis Sci 2005; 46(8): 2932-2939.

20 Guo L, Salt TE, Maass A, Luong V, Moss SE, Fitzke FW et al. Assessment of neuroprotective effects of glutamate modulation on glaucoma-related retinal ganglion cell apoptosis in vivo. Invest Ophthalmol Vis Sci 2006; 47(2): 626-633.

21 Guo L, Salt TE, Luong V, Wood N, Cheung W, Maass A et al. Targeting amyloid-beta in glaucoma treatment. Proc Nat Acad Sci USA 2007; 104(33): 13444-13449.

22 Krupin T, Liebmann JM, Greenfield DS, Rosenberg LF, Ritch R, Yang JW. The Low-pressure Glaucoma Treatment Study (LoGTS): study design and baseline characteristics of enrolled patients. Ophthalmology 2005; 112(3): 376-385.

23 Garway-Heath DF, Crabb DP, Bunce C, Lascaratos G, Amalfitano F, Anand $\mathrm{N}$ et al. Latanoprost for open-angle glaucoma (UKGTS): a randomised, multicentre, placebocontrolled trial. Lancet 2014; 385(9975): 1295-1304.

24 Harwerth RS, Wheat JL, Rangaswamy NV. Age-related losses of retinal ganglion cells and axons. Invest Ophthalmol Vis Sci 2008; 49(10): 4437-4443.

25 Curcio CA, Allen KA. Topography of ganglion cells in human retina. J Comp Neurol 1990; 300(1): 5-25.

26 Spear PD, Kim CBY, Ahmad A, Tom BW. Relationship between numbers of retinal ganglion cells and lateral geniculate neurons in the rhesus monkey. Vis Neurosci 1996; 13(01): 199-203.

27 Williams RW, Strom RC, Rice DS, Goldowitz D. Genetic and environmental control of variation in retinal ganglion cell number in mice. J Neurosci 1996; 16(22): 7193-7205.

28 Huang D, Swanson EA, Lin CP, Schuman JS, Stinson WG, Chang W et al. Optical coherence tomography. Science 1991; 254(5035): 1178-1181.

29 Van Velthoven MEJ, Verbraak FD, Yannuzzi LA, Rosen RB, Podoleanu AGH, de Smet MD. Imaging the retina by en face optical coherence tomography. Retina 2006; 26(2): 129-136.

30 Costa RA, Skaf M, Melo LASJ, Calucci D, Cardillo JA, Castro JC et al. Retinal assessment using optical coherence tomography. Prog Retin Eye Res 2006; 25(3): 325-353.

31 Chauhan BC, Stevens KT, Levesque JM, Nuschke AC, Sharpe GP, O'Leary N et al. Longitudinal in vivo imaging of retinal ganglion cells and retinal thickness changes following optic nerve injury in mice. PloS One 2012; 7(6): e40352.

32 Guo L, Normando EM, Nizari S, Lara D, Cordeiro MF. Tracking longitudinal retinal changes in experimental ocular hypertension using the cSLO and spectral domain-OCT. Invest Ophthalmol Vis Sci 2010; 51(12): 6504-6513.

33 Bussel II, Wollstein G, Schuman JS. OCT for glaucoma diagnosis, screening and detection of glaucoma progression. Br J Ophthalmol 2014; 98(Suppl 2): ii15-ii19.

34 Schuman JS. Spectral domain optical coherence tomography for glaucoma (an AOS thesis). Trans Am Ophthalmol Soc 2008; 106: $426-458$

35 Werkmeister RM, Dragostinoff N, Pircher M, Gotzinger E, Hitzenberger CK, Leitgeb RA et al. Bidirectional Doppler Fourier-domain optical coherence tomography for measurement of absolute flow velocities in human retinal vessels. Opt Lett 2008; 33(24): 2967-2969. 
36 Pircher M, Hitzenberger CK, Schmidt-Erfurth U. Polarization sensitive optical coherence tomography in the human eye. Prog Retin Eye Res 2011; 30(6): 431-451.

37 Keane PA, Ruiz-Garcia H, Sadda SR. Clinical applications of long-wavelength $(1,000-\mathrm{nm})$ optical coherence tomography. Ophthalmic Surg Lasers Imaging 2011; 42(Suppl): S67-S74.

38 Webb RH, Hughes GW, Pomerantzeff O. Flying spot TV ophthalmoscope. Appl Opt 1980; 19(17): 2991-2997.

39 Chauhan BC. Confocal scanning laser tomography. Can J Ophthalmol 1996; 31(3): 152-156.

40 Webb RH, Hughes GW, Delori FC. Confocal scanning laser ophthalmoscope. Appl Opt 1987; 26(8): 1492-1499.

41 Zangwill LM, Bowd C. Retinal nerve fiber layer analysis in the diagnosis of glaucoma. Curr Opin Ophthalmol 2006; 17(2): 120-131.

42 Leung CKS, Lindsey JD, Crowston JG, Ju W-K, Liu Q, Bartsch D-U et al. In vivo imaging of murine retinal ganglion cells. J Neurosci Methods 2008; 168(2): 475-478.

43 Cordeiro MF, Migdal C, Bloom P, Fitzke FW, Moss SE. Imaging apoptosis in the eye. Eye 2011; 25(5): 545-553.

44 Higashide T, Kawaguchi I, Ohkubo S, Takeda H, Sugiyama $\mathrm{K}$. In vivo imaging and counting of rat retinal ganglion cells using a scanning laser ophthalmoscope. Invest Ophthalmol Vis Sci 2006; 47(7): 2943-2950.

45 Maass A, von Leithner PL, Luong V, Guo L, Salt TE, Fitzke FW et al. Assessment of rat and mouse RGC apoptosis imaging in vivo with different scanning laser ophthalmoscopes. Curr Eye Res 2007; 32(10): 851-861.

46 Cilkova M, Matlach J, Chopra R, Rider A, Shah N, Mulholland $\mathrm{P}$ et al. Repeatability and inter-observer variability of in vivo retinal cone imaging using a modified Heidelberg Retinal Angiography (HRA2) in normal subjects. 471 High Resolution Photoreceptor Imaging, 2015. Available from http://www.arvo.org/webs/am2015/abstract/471.pdf.

47 Miller DT, Kocaoglu OP, Wang Q, Lee S. Adaptive optics and the eye (super resolution OCT). Eye 2011; 25(3): 321-330.

48 Liang J, Grimm B, Goelz S, Bille JF. Objective measurement of wave aberrations of the human eye with the use of a Hartmann-Shack wave-front sensor. J Opt Soc Am A Opt Image Sci Vis 1994; 11(7): 1949-1957.

49 Chen TC, Cense B, Pierce MC, Nassif N, Park BH, Yun SH et al. Spectral domain optical coherence tomography: ultra-high speed, ultra-high resolution ophthalmic imaging. Arch Ophthalmol 2005; 123(12): 1715-1720.

50 Truong SN, Alam S, Zawadzki RJ, Choi SS, Telander DG, Park SS et al. High resolution Fourier-domain optical coherence tomography of retinal angiomatous proliferation. Retina 2007; 27(7): 915-925.

51 Biss DP, Sumorok D, Burns SA, Webb RH, Zhou Y, Bifano TG et al. In vivo fluorescent imaging of the mouse retina using adaptive optics. Opt Lett 2007; 32(6): 659-661.

52 Williams DR. Imaging single cells in the living retina. Vision Res 2011; 51(13): 1379-1396.

53 Chen MF, Chui TYP, Alhadeff P, Rosen RB, Ritch R, Dubra A et al. Adaptive optics imaging of healthy and abnormal regions of retinal nerve fiber bundles of patients with glaucoma. Invest Ophthalmol Vis Sci 2015; 56(1): 674-681.

54 Battu R, Dabir S, Khanna A, Kumar AK, Roy AS. Adaptive optics imaging of the retina. Indian J Ophthalmol 2014; 62(1): 60-65.

55 Köbbert C, Apps R, Bechmann I, Lanciego JL, Mey J, Thanos S. Current concepts in neuroanatomical tracing. Prog Neurobiol 2000; 62(4): 327-351.
56 Thanos S, Fischer D, Pavlidis M, Heiduschka P, Bodeutsch N. Glioanatomy assessed by cell-cell interactions and phagocytotic labelling. J Neurosci Methods 2000; 103(1): 39-50.

57 Gray DC, Wolfe R, Gee BP, Scoles D, Geng Y, Masella BD et al. In vivo imaging of the fine structure of rhodaminelabeled macaque retinal ganglion cells. Invest Ophthalmol Vis Sci 2008; 49(1): 467-473.

58 Naskar R, Wissing M, Thanos S. Detection of early neuron degeneration and accompanying microglial responses in the retina of a rat model of glaucoma. Invest Ophthalmol Vis Sci 2002; 43(9): 2962-2968.

59 Thanos S, Naskar R, Heiduschka P. Regenerating ganglion cell axons in the adult rat establish retinofugal topography and restore visual function. Exp Brain Res 1997; 114(3): 483-491.

60 Thanos S, Indorf L, Naskar R. In vivo FM: using conventional fluorescence microscopy to monitor retinal neuronal death in vivo. Trends Neurosci 2002; 25(9): 441-444.

61 Thanos S, Naskar R. Correlation between retinal ganglion cell death and chronically developing inherited glaucoma in a new rat mutant. Exp Eye Res 2004; 79(1): 119-129.

62 Leak RK, Moore RY. Identification of retinal ganglion cells projecting to the lateral hypothalamic area of the rat. Brain Res 1997; 770(1-2): 105-114.

63 Cordeiro MF, Guo L, Coxon KM, Duggan J, Nizari S, Normando EM et al. Imaging multiple phases of neurodegeneration: a novel approach to assessing cell death in vivo. Cell Death Dis 2010; 1: e3.

64 Sabel BA, Engelmann R, Humphrey MF. In vivo confocal neuroimaging (ICON) of CNS neurons. Nat Med 1997; 3(2): 244-247.

65 Vidal-Sanz M, Salinas-Navarro M, Nadal-Nicolas FM, Alarcon-Martinez L, Valiente-Soriano FJ, de Imperial JM et al. Understanding glaucomatous damage: anatomical and functional data from ocular hypertensive rodent retinas. Prog Retin Eye Res 2012; 31(1): 1-27.

66 Salinas-Navarro M, Jiménez-López M, Valiente-Soriano FJ, Alarcón-Martínez L, Avilés-Trigueros M, Mayor S et al. Retinal ganglion cell population in adult albino and pigmented mice: a computerized analysis of the entire population and its spatial distribution. Vision Res 2009; 49(6): 637-647.

67 Salinas-Navarro M, Mayor-Torroglosa S, Jiménez-López M, Avilés-Trigueros M, Holmes TM, Lund RD et al. A computerized analysis of the entire retinal ganglion cell population and its spatial distribution in adult rats. Vision Res 2009; 49(1): 115-126.

68 Bodeutsch N, Thanos S. Migration of phagocytotic cells and development of the murine intraretinal microglial network: an in vivo study using fluorescent dyes. Glia 2000; 32(1): 91-101.

69 Wang X, Archibald ML, Stevens K, Baldridge WH, Chauhan BC. Cyan fluorescent protein (CFP) expressing cells in the retina of Thy1-CFP transgenic mice before and after optic nerve injury. Neurosci Lett 2010; 468(2): 110-114.

70 Hermann B, Fernandez EJ, Unterhuber A, Sattmann H, Fercher AF, Drexler W et al. Adaptive-optics ultrahighresolution optical coherence tomography. Opt Lett 2004; 29(18): 2142-2144.

71 Leung CK, Weinreb RN, Li ZW, Liu S, Lindsey JD, Choi N et al. Long-term in vivo imaging and measurement of dendritic shrinkage of retinal ganglion cells. Invest Ophthalmol Vis Sci 2011; 52(3): 1539-1547. 
72 Leung CKS, Lindsey JD, Chen L, Liu Q, Weinreb RN. Longitudinal profile of retinal ganglion cell damage assessed with blue-light confocal scanning laser ophthalmoscopy after ischaemic reperfusion injury. Br J Ophthalmol 2009; 93(7): 964-968.

73 Leung CK, Lindsey JD, Crowston JG, Lijia C, Chiang S, Weinreb RN. Longitudinal profile of retinal ganglion cell damage after optic nerve crush with blue-light confocal scanning laser ophthalmoscopy. Invest Ophthalmol Vis Sci 2008; 49(11): 4898-4902.

74 Dezawa M, Takano M, Negishi H, Mo X, Oshitari T, Sawada H. Gene transfer into retinal ganglion cells by in vivo electroporation: a new approach. Micron 2002; 33(1): 1-6.

75 Zheng QA, Chang DC. High-efficiency gene transfection by in situ electroporation of cultured cells. Biochim Biophys Acta 1991; 1088(1): 104-110.

76 Nickerson JM, Goodman P, Chrenek MA, Johnson CJ, Berglin L, Redmond TM et al. Subretinal delivery and electroporation in pigmented and nonpigmented adult mouse eyes. Methods Mol Biol 2012; 884: 53-69.

77 Garcia-Frigola C, Carreres MI, Vegar C, Herrera E. Gene delivery into mouse retinal ganglion cells by in utero electroporation. BMC Dev Biol 2007; 7: 103.

78 Nickerson JM, Getz SE, Sellers JT, Chrenek MA, Goodman P, Bernal CJ et al. DNA delivery in adult mouse eyes: An update with corneal endothelium outcomes. Methods Mol Biol 2014; 1121: 165-177.

79 Matsuda T, Cepko CL. Electroporation and RNA interference in the rodent retina in vivo and in vitro. Proc Natl Acad Sci USA 2004; 101(1): 16-22.

80 Nadal-Nicolas FM, Jimenez-Lopez M, Salinas-Navarro M, Sobrado-Calvo P, Alburquerque-Bejar JJ, Vidal-Sanz $\mathrm{M}$ et al. Whole number, distribution and co-expression of brn3 transcription factors in retinal ganglion cells of adult albino and pigmented rats. PLoS One 2012; 7(11): e49830.

81 Surgucheva I, Weisman AD, Goldberg JL, Shnyra A, Surguchov A. Gamma-synuclein as a marker of retinal ganglion cells. Mol Vis 2008; 14: 1540-1548.

82 Surgucheva I, Surguchov A. Gamma-synuclein: cell-typespecific promoter activity and binding to transcription factors. J Mol Neurosci 2008; 35(3): 267-271.

83 Rodriguez AR, de Sevilla Müller LP, Brecha NC. The RNA binding protein RBPMS is a selective marker of ganglion cells in the mammalian retina. J Comp Neurol 2014; 522(6): 1411-1443.

84 Smith CA, Chauhan BC. Imaging retinal ganglion cells: enabling experimental technology for clinical application. Prog Retin Eye Res 2015; 44: 1-14.
85 Aman AT, Fraser S, Merritt EA, Rodigherio C, Kenny M, Ahn $\mathrm{M}$ et al. A mutant cholera toxin B subunit that binds GM1-ganglioside but lacks immunomodulatory or toxic activity. Proc Natl Acad Sci USA 2001; 98(15): 8536-8541.

86 Sánchez J, Holmgren J. Cholera toxin - a foe \& a friend. Indian J Med Res 2011; 133(2): 153-163.

87 Bhattacharya SK, Lee RK, Grus FH The Seventh ARVO/Pfizer Ophthalmics Research Institute Conference Working Group. Molecular Biomarkers in Glaucoma. Invest Ophthalmol Vis Sci 2013; 54(1): 121-131.

88 Meers P, Mealy T. Calcium-dependent annexin V binding to phospholipids: Stoichiometry, specificity, and the role of negative charge. Biochemistry 1993; 32(43): 11711-11721.

89 Nick Wood NH, Guo L, Francesca Cordeiro M. Imaging individual ganglion cells in the human retina. In: Grehn F, Stamper R (eds). Glaucoma, Springer: Berlin, Heidelberg, Germany, 2009, pp 1-12. Available from: http://dx.doi.org/10.1007/978-3-540-69475-5_1.

90 D'Arceuil H, Rhine W, de Crespigny A, Yenari M, Tait JF, Strauss WH et al. 99mTc annexin V imaging of neonatal hypoxic brain injury. Stroke 2000; 31(11): 2692-2700.

91 Galvao J, Davis BM, Cordeiro MF. In vivo imaging of retinal ganglion cell apoptosis. Curr Opin Pharmacol 2013; 13(1): 123-127.

92 Guo L, Cordeiro MF. Assessment of neuroprotection in the retina with DARC. Prog Brain Res 2008; 173: 437-450.

93 Schmitz-Valckenberg S, Guo L, Maass A, Cheung W, Vugler A, Moss SE et al. Real-time in vivo imaging of retinal cell apoptosis after laser exposure. Invest Ophthalmol Vis Sci 2008; 49(6): 2773-2780.

94 Baltmr A, Duggan J, Nizari S, Salt TE, Cordeiro MF. Neuroprotection in glaucoma - is there a future role? Exp Eye Res 2010; 91(5): 554-566.

95 Maxwell D, Chang Q, Zhang X, Barnett EM, Piwnica-Worms D. An improved cell-penetrating, caspase-activatable, nearinfrared fluorescent peptide for apoptosis imaging. Bioconjug Chem 2009; 20(4): 702-709.

96 Qiu X, Johnson JR, Wilson BS, Gammon ST, Piwnica-Worms D, Barnett EM. Single-cell resolution imaging of retinal ganglion cell apoptosis in vivo using a cell-penetrating caspase-activatable peptide probe. PloS One 2014; 9(2): e88855.

97 Bullok K, Piwnica-Worms D. Synthesis and characterization of a small, membrane-permeant, caspase-activatable far-red fluorescent peptide for imaging apoptosis. J Med Chem 2005; 48(17): 5404-5407. 